Cómo citar este artículo en Chicago: Osorio Herrera, Bayron y Luis Bayardo Getial Chalacan. "Noches lúgubres, de José Cadalso: la posibilidad de la noche para develar al otro”. Escritos 29, no. 62 (2021): 172-192. doi: http://dx.doi.org/10.18566/escr.v29n62.a10

Fecha de recepción: 18.02 .2021

Fecha de aceptación: 12.04 .2021

\title{
Noches lúgubres, de José Cadalso: la posibilidad de la noche para develar al otro ${ }^{1}$
}

\author{
José Cadalso's Noches Lúgubres: The Possibility of Night to Unveil the Other
}

\author{
Bayron León Osorio Herrera ${ }^{2}$ \\ Luis Bayardo Getial Chalacan ${ }^{3}$
}

\begin{abstract}
RESUMEN
Este artículo tiene como intención reflexionar, a partir de la obra de José Cadalso, Noches lúgubres, sobre las posibilidades del reconocimiento del otro como condición fundamental para un proceso efectivo de alteridad. La figura del protagonista, Tediato, sumido en la más densa oscuridad, permite el reconocimiento de una condición existencial al límite que necesita la presencia del otro para poder develar otra opción de sentido. Una dinámica de reencuentro consigo mismo es la condición para la apertura al rostro del otro que se me presenta como una nueva posibilidad existencial, porque el sentido vital de la existencia depende, en gran medida, de la relación que se construye con los otros. De ahí la importancia capital de comprender que el ser humano se hace humano en la medida en que tiene la capacidad de salir de sí mismo para donarse sin reciprocidad.
\end{abstract}

Palabras clave: Otredad; Noche; José Cadalso; Noches lúgubres; Diálogo; Alteridad.

\begin{abstract}
Considering José Cadalso's Noches Lúgubres [Lugubrious Nights], the article reflects on the possibilities of recognizing the other as a condition for an effective process of alterity. In Tediato, the main character and who is plunged into darkness, it is possible to recognize an existential condition pushed to the limit, which needs the presence of the other to unveil another possibility of meaning. A reunion with oneself is, then, the condition for an opening to the other, which appears as a new existential possibility because the vital meaning of existence depends largely on our relationship with others. Hence, the relevance of understanding that human beings become human as long as they have the ability of coming out of themselves to give themselves without reciprocity.
\end{abstract}

Keywords: Otherness; Night; José Cadalso; Noches Lúgubres; Dialogue; Alterity.

1 Este artículo hace parte de los resultados de investigación del proyecto de investigación "Contextos actuales de la antropología filosófica: perspectivas". Radicado 863B-07/17-42.

2 Doctor en Teología. Coordinador del Grupo de Investigación Epimeleia (ETFH), Universidad Pontificia Bolivariana. Correo: bayron.osorio@upb.edu.co.

3 Licenciado en Filosofía y Letras. Universidad Pontificia Bolivariana. Correo: luis.getial@upb.edu.co 


\section{Introducción}

$\mathrm{L}$ a obra dramática de Cadalso Noches lúgubres está compuesta por tres actos en forma de diálogo, que tienen lugar durante tres noches consecutivas. Cada una de las noches le ofrece al lector distintas posibilidades de comprensión e interpretación acerca de diferentes estados de pensamiento, sentimiento y actuación del ser humano encarnado en cada uno de los personajes de la obra literaria.

Cuando se piensa en el género literario del soliloquio, ${ }^{4}$ se reconoce, comprende e identifica que el protagonista de la obra literaria busca, a través de un personaje conceptual, dar a conocer su propio punto de vista sobre diferentes asuntos de la vida humana. En el caso de Noches lúgubres, de José Cadalso, el objeto de su diálogo resalta el papel que tiene el amor para el ser humano, pero, en especial, confronta, por medio del personaje de Tediato, distintas perspectivas de pensamiento que desde el amor se crean, piensan y construyen. Lo mismo que suscitar otras comprensiones e interpretaciones luego de la pérdida del ser amado, como en el caso del protagonista.

En cada una de las tres noches en que transcurre la obra literaria, el lector dilucida que Tediato utiliza la figura de Lorenzo para poder llevar a cabo su objetivo: llegar a la tumba de su amada, con la finalidad de encontrarse con ella, y así mostrar que el amor no se queda solo en el plano de la vida, sino que también trasciende el de la muerte como momento decisivo de encuentro.

En el género literario del soliloquio, el autor no solo confronta, reconoce, identifica o suscita nuevos modos del amor gracias a los personajes de la obra literaria, sino que reflexiona sobre cómo esta pasión genera nuevas formas de pensar, sentir y actuar en la condición humana y propicia un nuevo ser, otro, nuevas circunstancias o simplemente trastoca su cotidianidad.

Cuando el personaje Tediato se dedica al "rescate" de su amada en el cementerio con la ayuda de Lorenzo, no lo hace desde una fijación obsesiva, sino que más bien su intencionalidad tiene que ver con responder a su ser íntimo y a sus deseos más inmediatos. "A veces el personaje que monologa se limita a exponer en voz alta el curso de su pensamiento, imaginando, recordando, anticipando o también reflexionando y llegando a conclusiones, pero sin que su discurso se dirija específicamente a nadie".5

En este sentido, Tediato desea llevar a su domicilio el cuerpo de su amada e incendiar su casa para morir en ella con el fin de encontrarse en la vida eterna; ${ }^{6}$ quiere mostrar que el amor no es solo un sentimiento humano que se idealiza en la figura física del cuerpo amado, sino que también es una representación de los seres humanos para materializar el deseo final de la felicidad expresada en el vínculo efectivo con el

4 Véase Jesús Gómez, “El soliloquio de tradición agustiniana como límite del diálogo”, Revista de Literatura 66, n. ${ }^{\circ} 131$ (2004): 23-47.

5 Miguel Siguán Soler, “La expresión literaria del lenguaje interior”. Anuario de Psicología, n. 33 (1985): 120, acceso el 27 de abril de 2021, https://dialnet.unirioja.es/servlet/articulo? codigo=2943611.

6 La satisfacción del deseo es una oscura empresa cercana al horror; su protagonista, Tediato, se propone desenterrar el cuerpo de su amada solo para acostarse con ella y prender fuego a la casa. Para un desarrollo pormenorizado de esta idea, véase Samuel Monder, "La consumición del deseo: Acerca de las Noches lúgubres de José Cadalso", Acta Literaria, n. 34 (2007): 97-109, http://dx.doi.org/10.4067/S0717-68482007000100006. 
ser amado, y así muestra la dinámica del amor como una creación y re-creación que genera pensamiento, imaginación, recuerdo, memoria, olvido... y nos pone en el límite de nuestra existencia.

En la segunda noche, Tediato es difamado por un supuesto delito, sin embargo, él no se salvaguarda y acepta ser apresado; imagina en su mente que, a través de esta acción, podrá encontrarse con su amada en la vida eterna (en gran parte de la obra él es el mártir nunca habido), pero pronto es liberado al ser capturado el verdadero asesino. Sin embargo, Tediato continua con su pretensión de llevarse a su amada a casa en horas de la madrugada, y así cumplir con el cometido tramado con anterioridad.

En la última noche, Tediato continúa la intención de exhumar el cuerpo de su amada, pero se da cuenta del error a punto de cometer, más aún, comprende las consecuencias que tiene esta acción para su vida; pero, al mismo tiempo, logra percibir el sentido de otras eventualidades difíciles que le forjan una alteridad en sí mismo y en el mundo que lo rodea.

Se trata, entonces, de poder identificar en la obra literaria, en este caso en Noches lúgubres, algunos elementos para la comprensión de aspectos de la condición humana, en especial aquellos que nos vinculan a otras posibilidades existenciales presentes en los otros.

\section{Tediato, un individuo al límite}

Cuando se habla del concepto de límite en el ser humano, es porque se reconoce, comprende e identifica el carácter de finitud que este presenta a lo largo de su habitar en el mundo, pero, en especial, su capacidad de discernir, crear, sensibilizar o concientizar a los otros de esta misma situación. "Porque en el ser humano nada hay acabado, porque no vivimos en un final de trayecto, sino en un trayecto, porque somos finitos"?

De igual forma, cuando se reconoce como limitado, utiliza todo su acervo cultural para suscitar en los otros el desarrollo de su capacidad de análisis, crítica y reflexión sobre diferentes asuntos de su entorno social, cultural, político, económico e ideológico, para lo cual utiliza diferentes representaciones simbólicas que buscan no solo preservarse para la posteridad, sino comprender la causa y el efecto que cada acontecimiento de su tiempo histórico tiene para su lectura e interpretación del mundo individual y comunitario.

$\mathrm{Al}$ reconocerse la finitud de la condición humana, también se evidencia la incidencia que tienen los límites para la vida cotidiana de los seres humanos, para la formación de su ser, saber y hacer; pero, al mismo tiempo, se potencian al máximo sus posibilidades vitales y existenciales, puesto que el ser humano tiene un día, hora y lugar de nacimiento, pero el día, hora y lugar de su muerte no los tiene programados. Por eso, su existencia se convierte en un trayecto biográfico que tiene que construir; pese a su finitud y ambigüedad, le corresponde la tarea de recrear su vida en un universo simbólico para hacer frente a la contingencia.

Somos los límites del mundo. En razón de nuestras emociones, pasiones y usos lingüísticos, dotamos de sentido y significación al mundo de la vida en que habitamos. Abandonamos la siempre naturaleza e ingresamos en el universo del sentido (lo que, técnicamente, podemos llamar mundo). Pero a la vez

7 Joan-Carles Mèlich, Filosofía de la finitud (Barcelona: Herder, 2011), 44. 
constituimos un límite entre ese "mundo de vida" en el que habitamos y su propio más allá: el cerco de misterio que nos trasciende y que determina nuestra condición mortal. ${ }^{8}$

Tediato es un individuo al límite, puesto que con la muerte de su amada ha perdido a la persona a quien le expresaba sus más profundas emociones y pasiones sobre el mundo a través del sentimiento del amor, pero, en especial, también al ser que le ayudaba a encontrar una comprensión e interpretación sobre el sentido que tendría su existencia. Ella era su compañera de camino quien le enseñaba hasta dónde podría llegar en la medida de sus posibilidades; es ella quien también configura la realidad de los límites propios de su condición humana. La figura de la amada lo pone en relación directa con la realidad, en el reconocimiento efectivo del otro para poder comprender su sentido. Por eso, el tejido de interpretaciones es también un tejido de relaciones. "La finitud se expresa en la necesidad de establecer relaciones con los otros, en la necesidad ineludible de dar y de recibir"."

El personaje principal, al perder a su amada, quien era el ser humano que le señalaba sus límites, siente que su existencia es una desdicha; ella representaba su contacto con el mundo exterior, con el otro, con la alteridad, que lo transgredía para hallarle un sentido a su existencia en un escenario que tiene muchos misterios para los mortales; también era quien le generaba nuevos horizontes de comprensión e interpretación de la realidad. Despertaba sus sentimientos, lo incitaba a pensar, crear y construir un arquetipo del mundo que ambos dotaban de sentido a través del lenguaje, la palabra, el amor o los sentimientos que se tenían ambos.

Con la muerte de su amada, no solo pierde a su compañera de camino quien le ayuda a explicar, comprender y traducir cada uno de los acontecimientos de la existencia, sino que esta pérdida lo pone en una situación límite que lo obliga a reconfigurar el sentido de su vida y su posibilidades vitales, se ve impelido a crear otra representación simbólica que lo ayude a comunicarse con los otros seres humanos que habitan dentro de su tiempo histórico y que puedan ayudar a hacer frente a sus situaciones límites. Es en el espacio de la noche, silenciosa, penumbrosa o pensante, donde Tediato puede reflexionar para hallarle sentido a su vida; aunque en esa circunstancia, también puede venirle a la mente desarrollar el hecho más estrepitoso como el de llevarse el cuerpo de su amada del cementerio para su casa.

\section{Una interpretación de "la noche"}

De noche cada cosa asume formas más leves, más matizadas, casi mágicas. Todo se endulza y se atenúa, incluso las arrugas del rostro y las del alma.

Romano Battaglia

En Noches lúgubres, el autor describe el proceso de la noche como oscuro, pavoroso, silencioso, espantoso, pesadumbre, tedio o tristeza. A medida que se avanza en la lectura, el lector se da cuenta de

8 Eugenio Trías, Ética y condición humana (Barcelona: Península, 2000), 5.

9 Mèlich, Filosofía de la finitud, 48. 
que hay una sintonía con la génesis de los dioses contada por Hesíodo, en que se pueden vislumbrar algunas pautas para acercarse a la comprensión de la noche expuesta por Cadalso en su obra. Tediato muestra a la noche desde un panorama oscuro y de una incontable soledad en que se perciben algunas voces que provienen de la cárcel. ${ }^{10}$

Hesíodo refiere el origen de la noche. "Primeramente, por cierto, fue Abismo; y después, Gea de amplio seno". "De Abismo, Érebo y la negra Noche nacieron; y de la Noche, luego, Éter y Hemera nacieron, que ella concibió y parió, habiéndose a Érebo unido en amor". ${ }^{12}$ Esta descripción hecha por Hesíodo sobre el nacimiento de Noche y Érebo permite también reconocer la noche de Cadalso. Al leer a Hesíodo, va a descubrir la noche como el espacio donde se gesta una gran variedad de dioses, cuya intencionalidad puede indicar que algunos de ellos esconden un universo de misterio y fascinación instigando a encerrarse en la penumbra de la oscuridad. Por otro lado, la noche da la oportunidad de conocer unos seres luminosos y otros que tienden a encerrarse porque representan lo oscuro o a la maldad; en la tradición mitológica, Cadalso encuentra dioses con características muy definidas; infunden miedo, terror, pánico, a veces, asco por las actuaciones que estos tienen frente a los otros dioses. ${ }^{13}$ Por esto, constantemente se abre el debate acerca del poder mágico que tiene la noche en su carácter de infinito y la posibilidad que brinda de luminosidad para la manifestación de estos poderes mágicos, y el ocultamiento que debe hacerse de ellos, pese a su belleza, en otras tradiciones míticas.

Sin embargo, se debe considerar que todos los seres humanos, de manera directa e indirecta, poseemos el mismo origen de la Noche, puesto que somos una mezcla tremens fascinans (terrible pero fascinante). ${ }^{14}$ En últimas, Noche ofrece una serie de posibilidades de sentido en un mismo panorama que pueden generar magia para dejarnos seducir por el encanto que esconde, o, por el contrario, un terror que saca los sentimientos y las emociones más negativas en nosotros como espectadores de la noche.

Ahora bien, Érebo, la oscuridad, en la acepción latina, obscurus ${ }^{15}$ denota una realidad asociada a lo oscuro, tenebroso, difícil de comprender, incierto, oculto, secreto. Pero también este obsucuros spes hace alusión a una vaga esperanza. ${ }^{16}$ En otras palabras, se comprende que el tránsito por la noche-oscuridad provoca un efecto en el ser humano, en este caso en Tediato, de sentimientos y emociones encontrados, porque, al perder a su compañera de camino, tiene que reinventarse $y$, en especial, confrontarse consigo mismo para dar una nueva dirección a su vida en soledad, pero, de igual forma, crearse una serie de cuestionamientos que lo llevan a pensar su relación con los otros.

10 José Cadalso, Noches lúgubres (Freeditorial, 2012), 3, edición en PDF. https://freeditorial.com/es/books/nocheslugubres (último acceso: 20 de Enero de 2020).

11 Hesíodo. Teogonía (México: Universidad Autónoma de México, 1978), 192.

12 Hesíodo, Teogonía, 194.

13 Para un estudio completo de esta realidad y descripción de los dioses griegos, véase Robert Graves, Dioses y héroes de la antigua Grecia, trad. por Charles Serrat (Madrid: 1999).

14 Se refiere aquí al misterio que cada hombre posee. Rudolf Otto lo muestra como "lo oculto y secreto, lo que no es público, lo que no se concibe ni entiende, lo que no es cotidiano y familiar, sin que la palabra pueda caracterizarlo y denominarlo con mayor precisión en sus propias cualidades afirmativas". Rudolf Otto, Lo santo: Lo racional y lo irracional en la idea de Dios (Madrid: Alianza, 1996), 22.

15 Diccionario ilustrado latín: Latino-español, español-latino (Barcelona: Spes, 1982), 543.

16 Diccionario ilustrado latín: Latino-español, español-latino, 543. 
En la obra cadalsiana, el lector puede encontrar dos aspectos vinculados directamente con la noche y que actúan de manera directa en Tediato. El primero es que la realidad de la noche se desarrolla de manera procesual e intempestiva; puede generarse un reconocimiento de la luz que va apareciendo gradualmente o que de un momento a otro se pasa de lo oscuro a la contemplación de la luz del día. El segundo aspecto muestra la incidencia de la noche en la intimidad del personaje; sus pensamientos, sentimientos y emociones con respecto a la búsqueda de sentido y los interrogantes frente a su nueva posibilidad existencial, en ausencia de su amada, tienen como cómplice la noche. Quizá por esto la connotación de la noche en la obra tiene un matiz de sufrimiento, de agobio, de nostalgia y de desesperanza; esta situación padecida por el personaje lo lleva a ocultarse dentro de su casa con la intención de morir en dicho lugar. Esta noche, prefigurada en el texto, tiene una serie de significados asociados al miedo o al terror, posiblemente por su vínculo con la oscuridad. "iQué noche! La oscuridad, el silencio pavoroso". ${ }^{17}$ Constantemente este tipo de referencias se pueden encontrar. En boca de Tediato, imbuido en sus circunstancias, "la noche es tan oscura y espantosa". ${ }^{18}$

Por otra parte, cuando se percibe la relación tan estrecha entre noche y oscuridad, advertimos que existe un vínculo intrínseco con el dolor que cada uno de los personajes padece en ese espacio. "En fin, ya se habrá desvanecido la noche. Solo mi corazón aún permanece cubierto de densas y espantosas tinieblas. Para mí nunca sale el sol. Las horas todas se pasan en igual oscuridad para mí". ${ }^{19}$

Sin embargo, pese a este espanto y oscuridad, presente en la realidad de la noche, la súplica de Tediato, “Noche!, dilata tu duración”, ${ }^{20}$ muestra otra condición, un ruego para que la noche no se disipe. Aquí entra en juego lo que podríamos llamar un intermedio entre una noche espesa o densa y aquella que deja prefigurar una posibilidad de una luz que cada vez aparece menos tenue. "Pero $¿$ acaso la noche puede ser una protectora o más aún, una guarida? ... "Domina, noche, domina". ${ }^{21}$

Ya finalizando la obra, la noche adquiere una nueva significación. La conversación que Tediato tiene con el niño que lo ha esperado siempre lo lleva a una búsqueda del sentido de su propia existencia; quiere reconocer, comprender e identificar por qué se quiere salir de sí mismo en este momento de su existencia. Al parecer, Noche y Érebo han dado paso a los dioses luminosos. "Me has contado el estado de tu familia. Mañana nos veremos en el mismo puesto para proseguir nuestro intento, y te diré por qué no nos hemos visto esta noche hasta ahora. Te compadezco tanto como a mí mismo". ${ }^{22}$

Al parecer, la noche ha logrado su cometido, ha suscitado asombro y fascinación en el personaje. Tediato piensa en su existencia y sobre su posibilidad de crear vínculos consigo mismo, con los otros y con el mundo. La noche ha posibilitado un ejercicio de reconfiguración de la existencia y de condición de sentido que pueden sacar al personaje del abismo profundo en que ha quedado una vez que la ausencia de la amada se hace presente en su vida.

17 Cadalso, Noches lúgubres, 4.

18 Cadalso, Noches lúgubres, 5.

19 Cadalso, Noches lúgubres, 14

20 Cadalso, Noches lúgubres, 21.

21 Cadalso, Noches lúgubres, 21.

22 Cadalso, Noches lúgubres, 23. 
En la noche, Tediato vive el caos de su existencia, pero es en ella misma que vislumbra una posibilidad del re-encuentro consigo mismo. El niño sirve como detonador de una puerta que se abre a la esperanza y a la afirmación de la vida. Seguir afirmando la vida a pesar del absurdo. "Juzgar si la vida vale o no vale la pena de vivirla es responder a la pregunta fundamental de la filosofía.".

A lo largo de todas las escenas de la obra, la noche no está desprovista de sentido, puesto que el autor, a través de cada una de las significaciones que ella representa para su tradición histórica, las utiliza para darle un sentido a la existencia del protagonista y la búsqueda del sentido de su vida después de la muerte intempestiva de su amada.

De esta manera, podría señalarse que la noche depende de la vivencia interna, porque Tediato estaba destrozado y eso no le permitía encontrarse consigo mismo, pero era necesario que viviera esta experiencia. Hay un himno de Novalis, en los Himnos a la noche, que dirá: "Pero mi corazón, en secreto, permanece fiel a la Noche, y fiel a su hijo, el Amor creador". ${ }^{24}$ Aquí en esta estrofa está expuesta la noche de acuerdo con el estado anímico que el personaje está evidenciando cada día dentro de su vida cotidiana, además, según Gallardo, estos tienen como efecto en el ser humano que "los ánimos pueden surgir por una experiencia emocional densa, entendiendo a esta como aquella en la cual una emoción se activa con mucha intensidad”. 25

Por otro lado, podría decirse que el estado de ánimo, según este autor, incide de manera directa en el ser humano, puesto que las pérdidas personales suscitan un sinfín de sentimientos y emociones negativas. "Las pérdida personales tienden a disminuir el interés en el trabajo, y en la condición personal, por largos periodos de tiempo". ${ }^{26} \mathrm{Al}$ parecer, hay una relación directa entre la noche y todas nuestras experiencias humanas; permanecer en la noche modifica sustancialmente nuestra condición existencial. En algunos casos, podría parecer la noche o la oscuridad un privilegio para nuestro acontecer vital, en la medida en que es un escenario propicio para el encuentro consigo mismo; sin embargo, en muchos casos, es necesario vivir el caos y el dolor que precede o induce a la noche, y que puede permanecer toda la vida.

\section{El rostro del otro}

Tediato se encuentra sumergido en su propio límite. Su tragedia le muestra el carácter de su finitud, pero también lo lleva a la pregunta existencial por el sentido para sobreponerse de esta condición trágica. Se da cuenta de que solo en la creación de vínculos es posible una nueva condición para superar la miseria y la desazón con la que ahora enfrenta su existencia. La existencia humana es producto de los encuentros de amistad, afecto, amor, odio, tristeza y otro sinfín de sentimientos y circunstancias que ponen en consideración el valor de la vida. El límite hace tomar conciencia de la finitud y de la condición peregrina de la vida y la necesidad de darle una significación a través de una comprensión e interpretación del mundo aquí y ahora.

23 Albert Camus, El mito de Sísifo (Buenos Aires: Alianza, 1985), 5.

24 Novalis, Himnos a la noche (Madrid: Orbis, 1982), 10.

25 René Gallardo Vergara, “Naturaleza del estado de ánimo”, Revista Chilena de Neuropsicología 1, n. ${ }^{\circ} 1$ (2006): 29-49.

26 Gallardo Vergara, "Naturaleza del estado de ánimo”, 29. 
El ser humano a lo largo de su existencia busca a través de diferentes experiencias de mundo otras formas de vida, algunas le presentan promesas de un futuro más allá; le ofrecen diversas perspectivas que en algunos casos no es posible asegurar porque presentan un alto grado de abstracción en su lectura e interpretación.

En el mundo histórico, social y cultural, no se puede hablar de una sola perspectiva sobre el habitar, el pensar, el sentir y el actuar del ser humano, puesto que la vida se hace significativa de acuerdo con cada una de las experiencias de sentido que tenemos en nuestro devenir en el mundo; que, en muchos casos, termina dependiendo del valor que cada individuo le brinde al encontrarse inserto en el mundo. Este significado vital no puede prescindir de lo que los otros representan en mí; su presencia o ausencia tiene una influencia capital para el sentido o los sentidos que se pueden otorgar a la existencia. Y aunque es individual y finito, y representa una particularidad que lo diferencia y lo separa de los otros, sin el concurso de ellos, su vida puede carecer de sentido. Su vida cotidiana y todo su proyecto vital dependen, en gran medida, de la relación que establece con los otros.

Los otros representan, entonces, una posibilidad para la existencia. Ponen a prueba dicha existencia por todos los hechos y acontecimientos que se generan alrededor de ellos. Pero es en este escenario en que la búsqueda de sentido se configura en una tarea personal y una construcción particular que se vuelca comunitaria con el concurso de los otros que me interpelan y que son interpelados por mí existencia. Así el hombre crea y re-crea su existencia en relación directa con la presencia del otro. Su estado creador y de búsqueda de sentido lo pone en contacto con otras búsquedas y otros sentidos que determinan su condición creadora. En el caso de Tediato, inmerso en una profunda noche, experimenta un estado de creación, un estado de poiésis, que comienza a determinar su existencia. La oscuridad, presente en una parte de su trayecto biográfico y que lo sumerge en un ahogo emocional, en una penumbra del pensamiento y del sentido, comienza a disiparse por la presencia de los otros.

A este respecto, sería interesante traer un planteamiento de Buber cuando se refiere a la crisis del ser del hombre en el mundo, con lo que hace referencia al progreso de la humanidad, en términos capitalistas, pero que replantea el sentido de los seres humanos en esta carrera salvaje por el acumular, porque sigue siendo un ser finito y sin seguridades. El hombre "no camina a sus anchas por carretera abierta, sino que tienen que poner un pie tras otro por un angosto sendero entre abismos". ${ }^{27}$

El "progreso", el supuesto progreso, no ha menguado la condición frágil, finita, ambigua y contingente de los seres humanos que viven en la incertidumbre y en la angustia existencial. "Una existencia que por su esencia se halla a cada momento amenazada desde dentro y desde fuera y que está expuesta a crisis cada vez más profundas". 28

Crisis que por lo demás puede considerarse como una crisis humana, en la medida en que pone en riesgo la humanidad y todas sus posibles relaciones. Pero lo más importante pone en crisis nuestra realidad personal y el vínculo que tenemos con los otros. Si el otro representa para mí una posibilidad existencial, entonces, mi relación con él en estado de crisis me pone en un escenario de una posible crisis de sentido.

27 Martín Buber, Caminos de utopía (México: Fondo de Cultura Económica, 2014), 190.

28 Buber, Caminos de utopía, 190. 
Es imperativo, por tanto, enfrentar la crisis, no como una condición reaccionaria, sino con plena conciencia de su presencia y de la necesidad de reconciliarla. No basta identificarla, sino hay que aprehenderla, y esto es posible solo con un verdadero conocimiento de lo que genera dicha crisis. "Cuanto más grave sea la crisis, tanto más serio y consciente de la responsabilidad es el conocimiento que de nosotros se exige, puesto que, aunque lo que se exige es el hecho, solo el hecho esclarecido en el conocimiento contribuirá a vencer la crisis". ${ }^{29}$

En este sentido, siguiendo a Buber, se podría pensar que el ser humano vive en una constante crisis a lo largo de su existencia. En ocasiones, busca comprenderla intentando un conocimiento de sí mismo, del mundo y del entorno inmediato que lo rodea. Analiza y discurre sobre los acontecimientos cotidianos que le generan felicidad, angustia, soledad y dolor. En otras ocasiones, se sumerge y se deja intimidar por la crisis que lo deja inmóvil y, al parecer, sin opciones vitales.

Es el caso de Tediato, quien, fente al desafío de la muerte, se pone en el escenario reflexivo para decidir cómo enfrentarse a la vida o morir creyéndose un mártir del "amor" en una posición egocéntrica, que, en definitiva, solo exalta su "yo". Un "yo" distorsionado inmerso en una burbuja por temor a ser destruido, que no se da cuenta de que, en su agobio y su ensimismamiento frente a la realidad de la vida, desestima el esfuerzo continuo y la voluntad profunda que debe tener para ponerle freno a los deseos de extinguirse, y no dejarse llevar por los sentimientos y las emociones que nublan su visión a causa de la ausencia de su amada.

Este ensimismamiento y esta posición egocéntrica pone en riesgo la realidad de la vida en presencia de otro. Una vida marcada por el solipsismo se vuelve una vida centrada en el ego que desestima el encuentro y la realidad del otro, lo margina y lo vuelve invisible con la pretensión de que la única realidad posible y digna de consideración es la que atraviesa un individuo particular.

En el caso de Tediato, es gracias a la interacción que se da con Lorenzo y luego el niño en que puede asumir el efecto que tiene para su vida la experiencia del duelo, pero, en especial, logra direccionar desde otra perspectiva de pensamiento para irla superando y hallarle otro sentido.

Se da cuenta de que la única posibilidad de salir de la situación y superar la muerte de la amada está en la re-significación del mundo en presencia de los otros. "La carga más pesada es, por lo tanto, a la vez, la imagen de la más intensa plenitud de la vida". ${ }^{30}$ Pero solo se logra esto si, en efecto, el rostro del otro acontece en mí. En últimas, Tediato percibe que solo en la medida en que es capaz de reconocer la presencia del rostro del otro en su vida la existencia puede tomar otra dirección y sacarlo de la bruma que lo lleva a pensar en acabar con su existencia.

Tediato se encuentra sumergido en un dilema profundo que lo vuelve abstraído, solitario e introspectivo. La ausencia de su amada y la contemplación de su cuerpo inerte lo ponen en la situación de desesperanza inmediata al no poder estar con su ella; pero, por otro lado, en una febril esperanza de su reencuentro al morir. Por eso, ansía morir y maquina una situación que lo deja al límite de su vida.

29 Buber, Caminos de utopía, 191.

30 Milan Kundera, La insoportable levedad del ser (México: Incorporados, 2002), 5. 
El dolor por la pérdida de su referente del eros, ${ }^{31}$ su amada, lo ha sumergido en el miedo. Miedo que lo vuelve inmóvil frente a la vida y lo pone frente a la experiencia del sinsentido. Ya no ve para su existencia otra cosa que fatalidad, horror y desesperanza; no encuentra ahora una motivación para conservarla.

Sin embargo, con esta experiencia que lo lleva a reconocer al otro, se da cuenta de que, "cuanto más pesada sea la carga, más a ras de tierra estará nuestra vida, más real y verdadera será" ${ }^{2}$ Tediato está solo; aquella conexión con la vida se ha marchado, ha muerto. Las relaciones con el mundo se han roto y ahora todo carece de sentido. Pero se desvanece la oscuridad, el rostro del otro, el niño, lo vuelve a vincular con el mundo. Restablece sus relaciones con el otro, con los otros y cobra un nuevo aliento. En palabras de Camus: "cuando volvió a ver el rostro de este mundo, a gustar del agua y del sol, de las piedras cálidas y del mar, ya no quiso volver a la oscuridad infernal". ${ }^{33}$

El otro representa luz y claridad frente a la condición de existencia. Solo en esta referencia es posible otro sentido para la vida. Tediato redimensiona su soledad. Sabe que en la soledad no se pueden pronunciar las palabras primordiales "yo-tu". ${ }^{34} \mathrm{El}$ "tú" es fundamental para entrar en contacto con el mundo y con el otro. Son la condición necesaria para re-encontrarse con el mundo, para volver a establecer los vínculos perdidos. Palabras que indican la totalidad del ser, según Buber, se pronuncian con el "ser entero". Este descubrimiento es de capital importancia para poder habitar el mundo y sus vínculos existenciales, porque "las palabras primordiales no significan cosas, sino que indican relaciones". ${ }^{36}$

En un primer momento, Tediato carece de una interioridad relacional, manifiesta solo un deseo utilitarista en relación con el otro. El deseo de relación solo vincula al otro desde la perspectiva de necesidad, inicialmente para llevar a cabo sus planes. Quiere materializar todo aquello que está en su imaginación y que ha cosechado durante su soledad. “¿Vendrá, acaso? ¡Cobarde! ¿Le espantará este aparato que Naturaleza le ofrece?". 37

En principio, este deseo utilitarista lo hace entrar en relación con Lorenzo, por lo demás Lorenzo motivado, en primera instancia, por su recompensa; pero hay ciertos atisbos que muestran, más que un rechazo hacia los vínculos reales, una necesidad urgente de ser escuchado, de salir de su soledad y manifestar sus sentimientos. "No ve lo interior de mi corazón... ¡Cuánto más se horrorizaría!” ${ }^{88}$ Un deseo de ser comprendido, un deseo de experimentar solidaridad con su dolor, dolor que ahoga toda su existencia.

Tediato, en su noche, en completa oscuridad, oculta toda su condición existencial, pero es en ella misma que lanza un grito desesperado porque desea ser visto en medio de esa gran oscuridad. Hay deseo de

31 No se trata aquí de un uso peyorativo del término, sino de la realidad que comienza a operar en el personaje y que puede llevar a una comprensión distorsionada del amor. Esto se puede ver en detalle en Carlos Marcelo Barvarino, "La amistad: Del eros al ágape", Cuadernos del Tomás, n. 2 (2010): 105-125, acceso el 27 de abril de 2021, https:// dialnet.unirioja.es/servlet/articulo? codigo=3761290.

32 Kundera, La insoportable levedad del ser, 5.

33 Camus, El mito de Sísifo, 59.

34 Martín Buber, Yo y tú, trad. por Horacio Crespo (Buenos Aires: Nueva Visión, 1977), 7.

35 Buber, Yo y tú, 8.

36 Buber, Yo y tú, 7.

37 Cadalso, Noches lúgubres, 4.

38 Cadalso, Noches lúgubres, 4. 
develamiento, pero también una incapacidad de mostrar el rostro que ante la presencia del otro sigue oculto. Su "noche" solo deja ver sombras. Su permanencia en la oscuridad opaca cualquier posibilidad de relación. Cuando el interior carece de luz, las relaciones son asimétricas, todo deseo de vida se nubla. Lo que se desea ver es la interioridad que refleja el rostro del otro, y ver al otro que devela toda mi interioridad. "El rostro me habla y por ello me invita a una relación sin paralelo con un poder que se ejerce, ya sea de gozo o conocimiento" ${ }^{39}$

\section{Lorenzo: una radiografía desde Tediato}

La noche continúa y va llevando a su paso lo incomprensible, y hace sus efectos invisibles a la vista. Lorenzo aparece en la vida de Tediato y su centro de atención está fijado en un interés compensatorio. El dinero prefigura su entrada en la noche y al encuentro con Tediato. Ve en este encuentro la posibilidad de revindicar su infortunio. No tiene dinero y la muerte lo acecha.

En esta hora fatídica, Lorenzo es convocado para realizar y ser cómplice de la idea que ha albergado Tediato en su imaginación. En un primer momento, por los intereses de ambos, la relación se establece en términos utilitaristas. Lorenzo es llevado por su situación a ser presa fácil y Tediado aprovecha tal situación. El otro desaparece como "otro" y solo se encuentra en un escenario de invisibilidad que lo deshumaniza y cierra toda posibilidad de alteridad. La muerte es la que convoca y no hay espacio para la vida. "La muerte es un sueño que no sueña el dinero. El dinero no dice tú eres: el dinero dice cuánto" ${ }^{40}$ Lorenzo está presto a cumplir el deseo de su "señor", y así obtener el beneficio, que, en su "infantil" e "inocente" mirada, sería la respuesta a su pesar.

Tediato espera a Lorenzo y su percepción de aquel sepulturero deja al descubierto la realidad del otro en un aparente estado de miseria. “¿Si será de Lorenzo aquella luz trémula y triste que descubro? Suya será. ¿Quién sino él, y en este lance, y por tal premio, saldría de su casa? Él es. El rostro pálido, flaco, sucio, barbado y temeroso; el azadón y pico que trae al hombro, el vestido lúgubre, las piernas desnudas, los pies descalzos, que pisan con turbación; todo me indica ser Lorenzo, el sepulturero del templo, aquel bulto, cuyo encuentro horrorizaría a quien le viese. Él es, sin duda; se acerca; desembózame, y le enseño mi luz. Ya llega. ¡Lorenzo! ¡Lorenzo!”.41

Al parecer, bajo la mirada de Tediato, Lorenzo es una persona que vive su vida en una situación extrema, al límite. Sus condiciones vitales no son las más favorables, casi lamentables. Manifiesta su vida un ser humano en perfecta desprotección de los otros y, en últimas, de sí mismo. Su abandono personal da cuenta de un desinterés marcado en su propia persona.

39 Emmanuel Levinas, Totalidad e infinito: Ensayo sobre la exterioridad (Salamanca: Sígueme, 2002), 211.

40 Octavio Paz, Lo mejor de Octavio Paz (Barcelona: Seix Barral, 1989), 43.

41 Cadalso, Noches lúgubres, 4-5. 
Nada parece lastimar a Lorenzo, sus piernas desnudas y los pies descalzos ${ }^{42}$ hacen su camino tortuoso, pero, en su estado de "decadencia", no parece importar. Su camino lento y su desinterés por avanzar lo inmovilizan para el encuentro del otro.

La desesperanza lo acompaña, su propia tragedia no deja percibir las condiciones en que Tediato lo invita a obrar y materializar su cometido, que, por lo demás, es una acción ajena. Su vida inmóvil frente a los otros deja ver solo unas relaciones superficiales y desprovistas de todo tipo de comunicación.

Tanto los pies como sus manos, en el caso de Lorenzo, son el vehículo fundamental para aproximarse a las personas; sus pies se encuentran desnudos y descalzos, y sus manos ocupadas con las diferentes herramientas para la exhumación del cadáver. Las dos extremidades no están disponibles para convocar a una relación de donación. Por una parte, en el hecho de dar sin esperar nada a cambio y, por otra, la disposición de recibir sin la sensación de tener que retribuir.

Es un "bulto", por lo demás, con la capacidad de aterrorizar. Su aspecto descuidado indica, además, su despreocupación por la vida, una renuncia a cualquier estado vital que lo ponga en función de los otros. Sus pies, la fijación a la tierra y a la realidad, están descalzos. Pero esta realidad también lo pone en una condición de desprotección y desnudez frente a los demás, que posiblemente provocan una necesidad de alteridad y vínculo existencial con los otros.

Por otra parte, su oficio, sepulturero, marca una dimensión en la vida de Lorenzo. Es un oficio en solitario sin más concurso que la muerte. "Antes los hombres trabajaban a un nivel más humano, frecuentemente en oficios y artesanías, y mientras lo hacían conversaban entre ellos". ${ }^{43}$ Porque estos oficios son de encuentro, de diálogo, de alteridad. Lorenzo y su trabajo prefiguran unos modos de ser, de saber y de hacer, unidos inevitablemente a la soledad, la tristeza y la ausencia que deja la muerte. Ya su oficio prefigura un estado de soledad y de "renuncia" a los otros.

El trabajo de Lorenzo no genera un contacto, ningún vínculo. Su relación con la muerte no le permite reconocer la vida y su conciencia de sí queda desfigurada, pues no hay iguales que lo confronten y establezcan relaciones y vínculos con él. "Es en el encuentro con los demás seres humanos donde el hombre individual toma conciencia de que es un sujeto". Para que se dé un encuentro con los otros, este debe realizarse en presencia de humanidad, de la vida, en un diálogo permanente de conocimiento y acercamiento que fundamentan toda relación; un desplazamiento hacia el otro que lo pone en una dinámica vital de reconocimiento. "Somos lo que hacemos con nuestras relaciones, que se suponen acciones en tanto que estas son actos ejecutados y se convierten en a priori para nuevos actos. Estamos presentes en el movimiento. ${ }^{45}$

42 Cadalso, Noches lúgubres, 4.

43 Ernesto Sábato, La resistencia (Buenos Aires: Seix Barral, 2000), 27.

44 Cfr. Joseph Gevaert, El problema del hombre: Introducción a la antropología filosófica (Salamanca: Sígueme, 2003), 38.

45 Memo Ánjel, La significación de lo insignificante: Una provocación de lo que nos rodea y nos hacemos humanos en la teoría de Martín Buber (Medellín: Universidad Pontificia Bolivariana, 2016), 23. 
El ser humano es producto del movimiento real de cada una de las acciones que se generan al entrar en relación con los otros que, de manera directa e indirecta, dan vida o mínimamente provoca una serie de sentimientos, emociones, pensamientos y deseos que están ligados con cada uno de los actos que generamos desde nuestra experiencia de vida o condición de habitantes del mundo.

De esta misma manera, se hace notorio que Lorenzo es un hombre que ya no tiene nada que perder. Perdió todo lo que había poseído, pero, pese a estar en estas condiciones, sus pies desnudos son la muestra de que todavía es un hombre necesitado y que la presencia de los otros es vital para preservar la vida. En estas circunstancias, su vida, su "miserable" vida, todavía puede dejar una huella indeleble en la vida de Tediato. Una huella que deja ese contacto con la tierra, con la realidad en que yace el ser en el mundo a través de su propia experiencia.

\section{El diálogo como reconocimiento del otro}

Ciertamente, uno de los factores principales en este contexto es el diálogo que se va exteriorizando a medida que van transcurriendo las noches a lo largo de la narración, pero, en especial, a través de cada una de las acciones que los personajes van recreando según su rol dentro del relato. El diálogo se presenta aquí como el escenario propicio de encuentro y develación del otro. Es el diálogo el que permite el reconocimiento efectivo de la necesidad imperante de la presencia de los otros en mi vida. Solo cuando dirijo mi palabra al otro hay reconciliación con la vida y emerge precisamente otra perspectiva existencial mediada por la palabra porque "la palabra es la unión entre los hombres. Es una relación activa (con contenido de vida) para el entendimiento del mundo. Así, es una potencia-acción, en tanto se relaciona con otra palabra y crea con ella, ya en la frase, ya en la conversación". ${ }^{46}$

El diálogo devela el interior y deja salir todo aquello que somos mostrándonos en completa desnudez para los otros. El diálogo nos pone en evidencia, pero también nos posibilita el encuentro con otras realidades que viven los otros seres humanos. "En el diálogo somos confrontados con base con lo que sabemos y esperamos saber. Y el silencio de las palabras dichas es la esencia de la confrontación [...] de aquí que lo sin-suceder no sea diálogo, sino prejuicio". ${ }^{47}$

Requiere el diálogo total apertura para poder hacer un ejercicio de encuentro y reconciliación. Una palabra que se dirige al otro sin ninguna intención más que la comunicación y la apertura total del ser, de lo contrario, no sería más que palabrería vacía y sinsentido, que, antes de generar encuentro, trae consigo hostilidad e incomprensión. "En el vértigo todo es temible y desaparece el diálogo entre las personas. Lo que nos decimos son más cifras que palabras, contiene más información que novedad. La pérdida del diálogo ahoga el compromiso que nace entre las personas y que puede hacer del propio miedo un dinamismo que lo venza y les otorgue una mayor libertad". ${ }^{4}$

46 Ánjel, La significación de lo insignificante, 56.

47 Ánjel, La significación de lo insignificante, 57.

48 Sábato, La resistencia, 12. 
Inicialmente, la descripción que hace Tediato de Lorenzo solo trae cifras. Una evaluación muy superficial a partir de su aspecto. No se ha detenido en su personalidad o en las posibilidades de su ser o de lo que alberga en su interior. Al parecer, Tediato no sabe que, cuando se realiza este escaneo frívolo sobre un ser humano, no es más que la descripción que se tiene del individuo desde lo exterior y no define lo esencial y la verdadera identidad del ser. Por lo demás, lo que vemos en los otros, en muchas ocasiones, devela nuestro propio ser.

Esta mirada dispersa y externa quizá refleja la dificultad para aceptar lo que sucede en nuestro interior cuando la oscuridad se apodera de nosotros y la lucha constante para exteriorizarlo y hacerlo patente frente a los otros y poder salir de ese abismo. Esta mira vacía del otro lo cosifica, lo saca del nivel de humanidad y lo pone en el escenario de la utilidad porque no se dimensiona el valor de la persona en otras circunstancias diferentes de su exterioridad. Tediato, en su estado por la pérdida de su amada, no reconoce otro asunto que lo externo. Su comunicación con el otro solo se da en la esfera de la negación, del silencio y del ensimismamiento. En su oscuridad, queda inmóvil y con incapacidad de comunicación. Su palabra es un monólogo que no encuentra otro destinatario más que él mismo sumido en su desdicha. Solo le preocupa su estado volcándolo a una insensibilidad frente al otro. En su hermetismo no reconoce la presencia del otro quien es el único que lo puede sacar de ese letargo. "Cuando somos sensibles, cuando nuestros poros no están cubiertos de las implacables capas, la cercanía con la presencia humana nos sacude, nos alienta, comprendemos que es el otro el que siempre nos salva". ${ }^{4}$

Por otra parte, está la "luz trémula", que Tediato identifica en Lorenzo. Podría indicar un posible momento de conciencia en esta circunstancia de desdicha que comienza, en presencia del otro, a manifestarse, no con la claridad total de una luz intensa que devela todo, pero sí como el inicio de un proceso de claridad frente a los acontecimientos, tanto de la muerte de su amada como de la relación que establece con los otros.

Esta opacidad de la vida de Tediato, su "trémula" condición, se convierte, en principio, en la muralla que lo inmoviliza para reconocer la presencia del otro y establecer un diálogo con él; diálogo que podría liberarlo mediante una comunicación que devele su ser. La observación que Tediato tiene sobre Lorenzo se da en la completa abstracción que experimenta tras la muerte de su amada. Margina a Lorenzo de su vida y lo excluye inicialmente de toda su existencia porque "abstraer significa literalmente 'poner aparte', 'arrancar' [...] Lo abstraído es 'lo puesto aparte' y el acto de poner aparte es una abstracción. Cuando el poner aparte es mental y no físico la abstracción es un modo de pensar mediante el cual separamos algo de algo". ${ }^{50}$

En el caso Noches lúgubres, el concepto de abstracción representa un acto de deshumanización por parte de Tediato. Su abstracción reduce al hombre que ha llegado en la figura de Lorenzo. Lo cosifica y solo lo ve como una exterioridad que no acontece como motivo de interioridad. Olvida cualquier posibilidad de alteridad y de comunicación. Su monólogo no posibilita la palabra para el otro y cierra cualquier posibilidad de diálogo.

49 Sábato, La resistencia, 71.

50 José Ferrater Mora, "Abstracción y abstracto", en Diccionario de filosofía abreviado (Buenos Aires: Sudamericana, 1974), vol. a-k, p. 35. 


\section{Lorenzo: pasividad y vínculo}

Ahora Tediato reconoce la figura de Lorenzo y ve en él la posibilidad de llevar su cometido a feliz término. Pero Lorenzo solo está ahí, su modo de habitar el mundo en su pasividad y quietud será la dinámica de movilización para Tediato. Aquella figura de rostro pálido, flaco, sucio, barbado y temeroso cobrará sentido porque su realidad pondrá al descubierto que es, precisamente, esta supuesta carencia por su apariencia y por su pasividad quien pondrá en movimiento otras circunstancias para Tediato. En términos cristianos, el salvador viene "camuflado" o indefenso, sin elegancia ni artilugios, es despreciado y no reconocido. Lorenzo cumple unas de las funciones más desfavorables en relación con la vida, entierra muertos, pero esta realidad lo convierte en el dador de esperanza, porque, una vez "enterrada" la muerte, él continúa con la vida; los seres queridos se van, él lo sabe, pero la existencia debe seguir a pesar de su partida, también esto lo sabe Lorenzo.

Lorenzo, en sus circunstancias, es un sujeto pasivo que se eclipsa, pero también se insinúa a los otros con su presencia en orden a una necesidad manifiesta de alteridad. Sin embargo, no es inmediatamente una alteridad recíproca o que crea unos vínculos instantáneamente. Su vida no está vinculada a la convivencia con los seres humanos porque el primer encuentro con ellos se da en el escenario de la muerte, en que no hay ningún tipo de reciprocidad.

Es esta circunstancia de Lorenzo la que, paradójicamente, dinamiza la vida. La alteridad no está relacionada única y exclusivamente con unas situaciones favorables para existencia. Una vida plena, colmada de privilegios o en las mejores condiciones no garantiza en lo absoluto los términos de la alteridad. Lorenzo, con una vida marcada por el sufrimiento y el dolor, rodeado constantemente por la muerte, es quien puede hablar de la carga existencial de la vida y del valor que a esta le corresponde no por las condiciones externas, sino por la apertura y disposición para abrirse siempre a ella. Lorenzo muestra que, pese al absurdo de la existencia, es necesario seguir afirmando la vida. En el momento más oscuro y que implica una total quietud del ser, aparece al mismo tiempo todo aquello que se necesita para dar paso a su misma reconstitución. "Cuanto más me acosaban las tinieblas del mundo nocturno, más me aferraba al universo platónico, porque cuanto más grande es el tumulto interior, más nos sentimos inclinados a cerrarnos en algún orden". ${ }^{51}$

Es necesario ir más allá de lo visible. En el caso de Lorenzo, quien se presenta en toda la narración como un hombre sencillo, en medio de la noche y la oscuridad que no permiten ver más que una simple apariencia, su presencia será decisiva para la situación de Tediato. Aunque inicialmente la relación que se establece entre ambos es de mutua utilidad por un principio de necesidad, la dinámica del desvelamiento de la noche va a conducir paulatinamente a otras condiciones más favorables para la alteridad. El primer encuentro surge del temor, de la necesidad, de la renuncia a la vida, en presencia de la noche espesa y de una oscuridad abrazadora. En este escenario, solo cuenta el provecho que puedan sacar de la situación personal que vive cada uno. Es una relación utilitarista que implica para cada uno la retribución en provecho propio. Situación que no genera, en principio, ninguna condición de alteridad porque para los seres humanos lo que construye vínculos vitales se da cuando un acto sale del hombre sin retorno. "La acción en sentido único es posible solo en la paciencia que, llevada al extremo, significa para aquel que

51 Sábato, La resistencia, 43. 
actúa: renunciar a ser el contemporáneo del propio resultado, actuar sin entrar en la tierra prometida". ${ }^{2}$ Lo que dinamiza, entonces, las relaciones humanas y que realmente crea vínculos para una verdadera alteridad solo ocurre en el terreno de la donación.

En un primer momento, la presencia de Lorenzo ya está pagada. La promesa de una recompensa por ejecutar el trabajo no muestra otra intencionalidad inicial de ser un agente pasivo que es movido solo por el interés. Esta realidad primera no genera más que una alteridad fraccionada e individual entre el hombre y el dinero.

Sin embargo, aunque Lorenzo aparece como un hombre consciente de su estado paupérrimo y de la necesidad imperante de la materialidad, tiene la capacidad de reflexionar sobre el momento que atraviesa en su existencia, a de diferencia de Tediato que ensimismado no ha elaborado, tampoco identificado, el sentido de esta experiencia. Lorenzo tiene una razón y una explicación para aceptar el trabajo y trabajar para él. “¡Cuán pobre seré cuando me atreví a prometerte lo que voy a cumplir! ¡Cuánta miseria me oprime! Piénsala tú, y yo... harto haré en llorarla. Vamos". ${ }^{33}$

Tediato ha convocado al "sacrilegio" sumido en un solipsismo que lo inmoviliza frente a la vida y, por eso, solo convoca a Lorenzo para seguir presenciando la muerte. El encuentro consigo mismo en la noche oscura manifiesta el producto de sus miedos, de sus temores, del rechazo a la vida, de la incapacidad de reconocer que es posible otra dirección para la existencia en ausencia de su amada. La presencia de Lorenzo, en el silencio de la noche y en pequeñez e infortunio, lo lleva a decidir a abrir su intimidad en presencia del otro como un reconocimiento a la interpelación que hace su sola presencia, o permanecer inmóvil en un acto egoísta sin el reconocimiento efectivo de la necesidad de la alteridad que lo increpa a manifestar la vida en otros escenarios.

\section{Desnudez y alteridad}

¿Qué hace el niño en medio de la oscuridad? ¿Qué hace la fragilidad expuesta? La figura del niño aparece en la segunda noche. Pese a su rápida mención, será de capital importancia en la elaboración que Tediato debe hacer de su experiencia y de la nueva expectativa de vida. La figura del niño no es ajena a la obra literaria ni aparece como un "comodín" para expresar someramente algunas realidades. En el momento de mayor auge, el romanticismo, en una época que prefigura grandes cambios sociales e históricos, la condición humana también es repensada y elaborada bajo otras ópticas. "Cuando se hizo necesario fabricar refugios mentales a los que poder huir, los románticos buscaron el que tenían más cerca: la infancia". ${ }^{4}$ No es gratuito que, en la concepción judeocristiana, por ejemplo, la imagen del niño esté presente bajo unas connotaciones muy significativas y determinantes para la adopción de una nueva vida (cfr. Mt. 18:3).

52 Emmanuel Levinas, La huella del otro (Mexico: Taurus, 2001), 55.

53 Cadalso, Noches lúgubres, 4.

54 Joaquín María Aguirre Romero, "Niño y poeta: La mitificación de la infancia en el romanticismo", Espéculo: Revista de Estudios Literarios, n. 9 (1998), acceso el 27 de abril de 2021, http://webs.ucm.es/info/especulo/numero9/ ninoroma.html. 
En la figura del niño, el protagonista reconocerá muchos de los aspectos de su personalidad y su incidencia será decisiva para su porvenir. El niño pone el escenario para otra forma de alteridad en la medida en que lleva al reconocimiento propio en el primer movimiento hacia un verdadero vínculo. Permite traer a la memoria la necesidad del reconocimiento de sí mismo y del otro sin el prejuicio o las ideas preconcebidas de un primer encuentro.

El primer asomo del niño pasa por un ejercicio de negación. No hay un estatuto de reconocimiento, es también un "bulto", no tiene ningún valor, asociado al abandono, a la soledad y a la oscuridad, pasa totalmente desapercibido o no es visto como alguien que pueda generar un provecho. Sin embargo, este es un primer acercamiento para develar la existencia del otro en la medida en que la negación es negación de algo o de alguien. En medio de la penumbra, aparece alguien, que, aunque, en primera instancia, no lo reconozca, siempre será un motivo de interrogación para recobrar el sentido. Tediato percibe la existencia del otro, no lo reconoce, pero percibe su presencia. "Amigo, ¿no respondes? Parece joven de corta edad. Niño, ¿quién eres? ¿Cómo has venido aquí?". ${ }^{55}$ No hay un reconocimiento inmediato, pero la presencia del otro, que impele a la pregunta, es un primer movimiento a una alteridad que puede quedar descubierta.

En este "pasajero" encuentro con un ser, en apariencia insignificante, se presenta la posibilidad de reinventarse, de recrear otra oportunidad en un movimiento de despojo que lo conduzca a un reconocimiento efectivo de la presencia del otro. Porque todo encuentro que pretenda crear vínculos solo es posible en el escenario del reconocimiento auténtico del rostro del otro, sin ninguna otra intención, más que un rostro que se presenta a otro rostro.

El rostro de la infancia, vinculado aquí a la figura del niño, pone a Tediato en otra situación que puede reconducir su vida. Es un ser indefenso, despojado, al parecer sin nigua posibilidad existencial. "Mi abuelo murió esta mañana. Tengo ocho años, y seis hermanos más chicos que yo. Mi madre acaba de morir de sobreparto. Dos hermanos tengo muy malos con viruelas, otro está en el hospital, mi hermana se desapareció desde ayer de casa". ${ }^{56}$ Esta condición del niño pone en movimiento otra situación para Tediato. Está en el escenario de la plena desnudez humana que muestra el abandono, la desprotección, la fragilidad, pero también la inocencia, la necesidad del cuidado, la protección... prescribe la inocencia y la total desnudez, y se da cuenta de la necesidad del otro. Lo pone en el plano de la simplicidad y de la sencillez de la vida, es un estado desprevenido y sin nada más que la vida misma.

El encuentro con el niño le muestra que la vida aparece tal cual es, desprovista de aditamentos externos y que lo único importante es la existencia pura y en acto. Volver al estado de inocencia, en que la vida transcurre sin ninguna intención diferente de la vida misma, dejar que ella transcurra y genere su propia dinámica. Tediato, ocupado y distraído con la muerte, ensimismado en su condición existencial del momento, se pierde la vida; es preso de su egoísmo al pretender que su estado y su condición son únicos y que merecen toda consideración. Se cree el centro del mundo y que cualquier otra existencia debe girar a su alrededor.

55 Cadalso, Noches lúgubres, 22.

56 Cadalso, Noches lúgubres, 22. 
Ahora la figura del niño, desprovista de cualquier atisbo de reconocimiento, precisamente porque se presenta en su total desnudez, moviliza en Tediato otro sentimiento y se da cuenta de que su existencia reclama el reconocimiento del otro y que su causa no puede ser la dinámica total de la vida. Por un momento su preocupación por sí mismo cesa y va develando la preocupación por el otro. "No llores; no quiero hacerte mal. Dime, ¿quién eres? ¿Dónde viven tus padres? ¿Sabes tu nombre? ¿Y el de la calle en que vives?". ${ }^{57}$

En este momento, Tediato pone una pausa a su preocupación y el sentimiento frente a su amada deja una puerta para que la alteridad vaya quedando al descubierto. Reconoce en el niño la necesidad del movimiento hacia el otro y que su situación también merece una consideración. "Pues no temas; dame la manita, toma ese pedazo de pan que me he hallado, no sé cómo, en el bolsillo y llévame a casa de tu padre".58

La preocupación de Tediato, por un momento, se convierte en preocupación por el otro. Pone dos planos de la existencia. El agobio por la situación que atraviesa, y lo instala en la condición de una vida pesada y al límite en el escenario de una vida que termina, y la realidad de una vida que comienza, en plena desnudez y que necesita ser reconocida porque no tiene nada más que ofrecer que su propia existencia. Volver al estado de infancia supone para Tediato el regreso al ser originario, sin el concurso de una vida mediada por el peso del pasado. El niño que representa la fragilidad y la desnudez también representa la posibilidad de una nueva esperanza y una vida que, a pesar de las adversidades, es una vida que comienza. En ese camino que ha estado plagado de oscuridad, es necesario recomenzar, volver al estado del anhelo y del sueño. Reconfigurar la vida y reivindicarse con la existencia. Esta reivindicación exige un volver a empezar, un "olvido" del peso y la carga que supone una vida vivida desde la óptica de la actividad diaria que ahoga y asfixia. Es necesario reencontrarse con ese ser interior que solo se percibe en la quietud y la inactividad externa, volver a ser el niño que no tiene otra ocupación que vivir. "El mundo infantil es ajeno a las complicaciones adultas; es simple en su inmediatez: El deseo se realiza en lo imaginario. En el mundo adulto, el deseo se ve refrenado por la realidad y las normas". ${ }^{9}$

Este encuentro fortuito con el niño genera, entonces, un movimiento de reconocimiento de sí mismo y del otro. Un movimiento que se configura en la necesidad de una alteridad que interpela la vida y la interroga en la base de la estructura y condición humana en orden al sentido. Un encuentro desprevenido, sin ningún prejuicio y sin ninguna intención de utilidad y provecho, reconfigura la vida y reconcilia con el pasado. El encuentro con otro sin condición, transparente y desnudo, pone en movimiento otro estatus para la vida y ayuda a recobrar el camino. "Tratar con el hombre en la prosperidad es tratarle fuera del mismo. Cuando está cargado de penas, entonces está cual es: cual Naturaleza lo entrega a la vida, y cual la vida le entregará a la muerte". ${ }^{0}$

La fragilidad humana expuesta en la carencia, pero también en el sinsentido, el encuentro de estas dos condiciones existenciales, activa el reconocimiento del otro y la posibilidad de un "rescate" de esta condición. Tediato en busca de la muerte se encuentra con la vida. La aparición del niño tiende una

57 Cadalso, Noches lúgubres, 22.

58 Cadalso, Noches lúgubres, 22.

59 Aguirre Romero, "Niño y poeta".

60 Cadalso, Noches lúgubres, 21. 
mano que posibilita el rescate, una nueva búsqueda de sentido para su existencia. Lo conduce a otra realidad en que, pese a la situación de dolor, es posible reencontrarse con la esperanza y con la vida.

El niño expone la humanidad de Tediato, una humanidad que parecía la única posible y la única digna de atención por su estado de sufrimiento. Es un "mártir del amor" y cree que es la única realidad posible y alrededor de la cual debe girar cualquier existencia. Pero este encuentro lo lleva a salir de sí mismo y reencontrarse con su "yo" en un estado de simpleza y desnudez, un estado de inocencia para recuperar su infancia, porque, cuando el hombre se aleja de la infancia, labra su perdición. "En su alma se marchita la inocencia, adentrándose en un mundo frío y oscuro; la alegría le abandona". ${ }^{61}$ En este estado, es capaz de reconocer que hay otras existencias que lo interpelan y que son vitales para la condición humana. Tediato asiste al reconocimiento de la fragilidad de otro ser que lo invita a caminar en la "oscuridad" para entrarse en las profundidades del ser y reconocer la luz interior que se despliega en presencia de otro. Es un camino de dos, un camino en presencia del rostro del otro que genera un diálogo preciso para el reconocimiento efectivo de cualquier alteridad. Una alteridad que devela por completo toda la condición humana en su necesidad de un movimiento constante que no olvide su estado primigenio. La humanidad debe estar en ese continuo devenir entre lo adulto y esa parte inocente que trata de ocultarse en los momentos de calamidad, mostrando que, gracias al ser del niño, se puede gestar la resistencia a las imposiciones de la sociedad, porque se piensa, crea y construye la personalidad a lo largo de nuestra propia existencia a través de nuestra parte del adulto, en que se puede alcanzar el equilibrio.

Gracias a esta alteridad descubierta, se opera un cambio sustancial en la vida de Tediato. El deseo vehemente de morir por su amada, como un gesto egoísta para satisfacer sus deseos, cambia radicalmente. Ahora su deseo esta puesto en la necesidad de acompañar la miseria de Lorenzo y su familia con su propia muerte en un gesto supremo de otredad. "Lorenzo, pues la suerte te ha dado tanta miseria y te la multiplica en tus deplorables hijos... Eres sepulturero... Haz un hoyo muy grande, entiérralos todos ellos vivos, y sepúltate con ellos. Sobre tu losa me mataré y moriré diciendo: Aquí yacen unos niños tan felices ahora como eran infelices poco ha, y dos hombres, los más míseros del mundo. ${ }^{62}$

\section{Conclusiones}

Se ha evidenciado que en la obra Noches lúgubres, de Cadalso, se encuentran elementos necesarios para una reflexión sobre la alteridad. Hoy, en una sociedad marcada, casi exclusivamente, por el individualismo, reconocer la presencia del otro se instaura como un principio fundamental para poder construir sociedades más humanas. El rostro, el rostro del otro, merece un reconocimiento y una significación especial en la vida. La búsqueda de sentido pasa necesariamente por el reconocimiento de la presencia de los otros en nuestras vidas. Lejos estamos de poder construir sociedades más fraternas si seguimos pensando que el otro, cualquier otro, es simplemente un "bulto" que aparece o desaparece sin ninguna incidencia real en nuestras vidas. No porque en principio no la tenga, sino porque nosotros mismos hemos marginado su presencia en un acto egoísta y pretencioso de autosuficiencia. Urge hoy relaciones

$61{ }^{57}$ Aguirre, "Niño y poeta".

62 Cadalso, Noches lúgubres, 23. 
más fraternas, más humanas, pero esto solo es posible si de verdad hay un ejercicio efectivo de una alteridad consciente, un reconocimiento de la presencia de los otros en nuestras vidas que nos interpela y nos abre al diálogo fraterno y sincero para juntos construir una posibilidad de sentido.

Por otra parte, se ha podido evidenciar la relación tan estrecha que se encuentra en la filosofía yla literatura. En este caso particular, la obra literaria permite la reflexión y desata toda una serie de interrogantes que dan cuenta de unas consideraciones de orden filosófico. La muerte, la vida, el sentido de estas, el vínculo, la condición existencial, el diálogo, la alteridad... han sido temas y motivos de grandes reflexiones y posiciones filosóficas. La literatura, en este caso concreto la obra dramática Noches lúgubres de Cadalso, enriquece y permite otros horizontes a la hora de abordar estos temas. La perspectiva que abre se suma a la realidad presente en la vida cotidiana que necesita seguir siendo pensada y reflexiona para poder encontrar cada vez nuevos caminos hacia unas posibilidades más en orden al sentido. Tanto la filosofía como la literatura, no solo tiene temas en común, sino que permiten unas consideraciones de tipo vital para los seres humanos. En palabras de Lyotard,

un artista o escritor posmoderno está en la posición de un filósofo: el texto que escribe, la obra que produce no están gobernados en principio, por reglas preestablecidas, y no pueden ser juzgados de acuerdo con un juicio determinante aplicando categorías familiares al texto o la obra. Esas reglas y categorías es lo que la obra de arte busca. El artista y el escritor, entonces trabajan sin reglas para formular las reglas de lo que habrá sido hecho. ${ }^{63}$

\section{Referencias}

Aguirre Romero, Joaquín María. "Niño y poeta: La mitificación de la infancia en el romanticismo”. Espéculo: Revista de Estudios Literarios, n. 9 (1998). Acceso el 27 de abril de 2021. http://webs.ucm.es/info/especulo/numero9/ ninoroma.html.

Ánjel, Memo. La significación de lo insignificante: Una provocación de lo que nos rodea y nos hacemos humanos en la teoría de Martín Buber. Medellín: Universidad Pontificia Bolivariana, 2016.

Barvarino, Carlos Marcelo. "La amistad: Del eros al ágape". Cuadernos del Tomás, n. 2 (2010): 105-125. Acceso el 27 de abril de 2021. https://dialnet.unirioja.es/servlet/articulo?codigo=3761290.

Buber, Martín. Caminos de utopía. México: Fondo de Cultura Económica, 2014.

Buber, Martín. Yo y tú. Traducido por Horacio Crespo. Buenos Aires: Nueva Visión, 1977.

Cadalso, José. Noches lúgubres. Freeditorial, 2012. Edición en PDF. https://freeditorial.com/es/books/nocheslugubres (último acceso: 20 de Enero de 2020).

Camus, Albert. El mito de Sísifo. Madrid: Alianza, 1985.

Diccionario ilustrado latín: Latino-español, español-latino. Barcelona: Spes, 1982.

Ferrater Mora, José. "Abstracción y abstracto". En Diccionario de filosofía abreviado. Buenos Aires: Sudamericana, 1974.

Gallardo Vergara, René. “Naturaleza del estado de ánimo”. Revista Chilena de Neuropsicología 1, n. 1 (2006): 29-49.

Gevaert, Joseph. El problema del hombre: Introducción a la antropología filosófica. Salamanca: Sígueme, 2003.

Gómez, Jesús. "El soliloquio de tradición agustiniana como límite del diálogo". Revista de Literatura 66, n. ${ }^{\circ} 131$ (2004): 23-47.

Graves, Robert. Dioses y héroes de la antigua Grecia. Traducido por Charles Serrat. Madrid: Milenium, 1999.

63 Jean-Frangois Lyotard, La posmodernidad (París: Gedisa, 1986), 25. 
Hesíodo. Teogonía. México: Universidad Autónoma de México, 1978.

Mèlich, Joan-Carles. Filosofía de la finitud. Barcelona: Herder, 2011.

Novalis. Himnos a la noche. Madrid: Orbis, 1982.

Hesíodo. Teogonía. México: Universidad Autónoma de México, 1978.

Kundera, Milan. La insoportable levedad del ser. México: Incorporados, 2002.

Levinas, Emmanuel. La huella del otro. México: Taurus, 2001.

Levinas, Emmanuel. Totalidad e infinito: Ensayo sobre la exterioridad. Salamanca: Sígueme, 2002.

Lyotard, Jean-Frangois. La posmodernidad. París: Gedisa, 1986.

Monder, Samuel. "La consumición del deseo: Acerca de las Noches lúgubres de José Cadalso". Acta Literaria, n. 34 (2007): 97-109. http://dx.doi.org/10.4067/S0717-68482007000100006.

Otto, Rudolf. Lo santo: Lo racional y lo irracional en la idea de Dios. Madrid: Alianza, 1996.

Paz, Octavio. Lo mejor de Octavio Paz. Barcelona: Seix Barral, 1989.

Sabato, Ernesto. La resistencia. Buenos Aires: Seix Barral, 2000.

Siguán Soler, Miguel. "La expresión literaria del lenguaje interior”. Anuario de Psicología, n. 33 (1985): 117-128.

Acceso el 27 de abril de 2021. https://dialnet.unirioja.es/servlet/articulo?codigo=2943611.

Trías, Eugenio. Ética y condición humana. Barcelona: Península, 2000. 